\title{
Extraction, Optimization, and Dyeing Standardization using Fresh Orange Citrus Peel on Cotton Fabrics
}

\author{
Nita Kusumawati $^{\mathrm{a}}$, Agus Budi Santoso ${ }^{\mathrm{b}}$, Asri Wijiastuti ${ }^{\mathrm{c}}$, Supari Muslim $^{\mathrm{b}, 1}$ \\ ${ }^{a}$ Department of Chemistry, Universitas Negeri Surabaya, Ketintang, Surabaya, 60231, Indonesia \\ E-mail: nkusumawati82@yahoo.com \\ ${ }^{b}$ Department of Electrical Engineering, Universitas Negeri Surabaya, Ketintang, Surabaya, 60231, Indonesia \\ E-mail: ${ }^{1}$ suparimuslim@gmail.com \\ ${ }^{\mathrm{c}}$ Department of Exceptional Education, Universitas Negeri Surabaya, Lidah Wetan, Surabaya, 60231, Indonesia \\ E-mail: zarahtulasri@yahoo.co.id
}

\begin{abstract}
This research was conducted to explore, characterize, and standardize the orange citrus peel utilization as one of the potential materials for eco-friendly dyeing on cotton. To find out the potential application has been conducted pre-mordant dyeing, which involves alum as mordant. Optimization of the interaction between the fibers, dye, mordant, and fixer, is done through the application of the different washing time, dyeing frequency, as well as fixer types. Orange citrus peel extract used in dyeing was obtained from water solvent extraction. To determine the presence of chromophores that determine the dyeing quality, a spectrum test was performed using a UV-Visible spectrophotometer. The results show that fixation with iron (II) sulfate, alum and lime have triggered an attractive color, namely golden yellow on iron (II) sulfate fixation, and light yellow, which are both produced in alum and lime fixation. Visual and instrumentation evaluation using Diffuse Reflectant Ultra Violet (DRUV) showed that different washing time, dyeing frequency, and fixers had affected the color strength. Specifically, the reflectance percentage produced was $86.54 \%$ $56.96 \%$ for washing times of $0-6 \mathrm{~h}$; and $78.95 \%-3.71 \%$ for the dyeing frequency $1-10$ times. The increase in color intensity that occurs along with a decrease in the reflectance percentage illustrates the potential magnitude for orange citrus peel skin to be further developed as a new natural dye with high economic value in the eco-friendly textile industry.
\end{abstract}

Keywords — natural dyes; orange citrus; peel; pre-mordanting; fixer.

\section{INTRODUCTION}

Citrus (Citrus SP.) is an annual fruit crop from Asia. Orange citrus is one of the fruit commodities that has an essential role in the world market, both in fresh and processed form [1]. The development of orange citrus production in the world tends to increase along with the development of broad harvests. World orange production in 2016 reached 124.24 million tons [2]. Indonesia ranks 9th as the largest citrus producer in the world. In 2015, the citrus surplus in Indonesia reached 1.70 million tons. Citrus surplus in Indonesia is projected to continue to increase to 2.02 million tons in 2019 [3]. The high quantity of world citrus production certainly brought a positive and negative impact. The positive impact generated refers to the high consumption of citrus fruits by the world's population. This relates to a number of health benefits presented by this fruit, including producers of vitamins, minerals and fiber [1], [4], non-bioactive nutrients that improve health and provide protection against chronic diseases, antioxidant, and inhibitors of fat accumulation [5].

While the negative impacts arising from the high quantity of world citrus production more lead to the high quantity of citrus peel waste, which increases with increasing consumption of this fruit. During this time, the citrus peels are generally directly dumped into the garbage that there's no benefit. This is unfortunate, given that its usefulness is very varied, one of them as the raw material for producing textile color [6].

The compounds contained in the citrus peel are hesperidin [7], [8], which is a group of flavonoids compounds that can be used as a producer of yellow color on textile materials. Hesperidin, 3',5,7-trihydroxy-4'-methoxy-flavanone-7-O- $\beta$ rutinoside, is the main active component of bioflavonoid found in Citrus reticulate peels (94 mg/100g dry wt.) [9][12]. Nevertheless, the benefit of hesperidin as the pigment is very weak because the pigments cannot be directly used as a dye. This has to be one of the reasons why the citrus peel is not much developed on the dyeing process using natural 
dyes in the past. Especially on the textile materials of cotton, the dyeing process becomes difficult because of this material made of cellulose fiber material that many are dominated by a reactive active compound such a negatively charged hydroxyl. A similar charge that owned by hesperidin pigment in the citrus peel material has inhibited interaction directly from the pigment compounds on cotton fabric fiber.

One procedure that can be done to increase the dyeing potential is through the use of mordant (intermediaries), which have active clusters with opposite charges to fibers and dyes. Thus, mordant will be a connector for the interaction between the hesperidin and cellulose fibers in cotton fabric [13], [14].

Mordanting is the stage where the fabric is treated using metal salts or other complex-forming agents so that it can bind mordantly natural dyes. Mordanting can be done either via the methods of pre mordanting, simultaneously mordanting, and post-mordanting. Mordant compounds with various types and selectivity or a combination of both can be applied on fabric fiber to get varied color shades, to increase interactions with dye, and to improve the fade resilience of the natural dyes. Extensive research in the area of research has been reported by reference [15]-[20]. To optimize the dyeing results, fixation becomes the next stage in the application of the natural dye. At this stage, the fixer locks the colors that interact with the fiber, both directly and through mordant intermediaries. Thus, the color intensity obtained remains stable because of the optimum fastness [21] [22]. The magnitude of the effect caused by mordanting and fixation on the intensity and fastness is strongly influenced by the type of fabric, dyes, mordant, dyeing method, fixer, processing time, and dyeing frequency. Therefore, it is necessary to do further research about the dyeing procedures standard, including the mordanting and fixation process, which can generate high color intensity on the dyeing using specific natural dyes from orange citrus peel extracts.

The purpose of this study is to standardize the dyeing development using orange citrus peels, which had only been considered as waste material becomes one of the next potential natural dyes raw materials. The color intensity and fastness improvement produced by orange citrus peel extract in this study were carried out through the optimization of different washing time, dyeing frequency, and fixers application. The successful use of citrus peel for textile dyeing will bring 2 (two) positive impacts, namely, the reduction of citrus peel in domestic waste and synthetic dyes waste, which is generally produced from non-optimum textile dyeing [20].

\section{MATERIAL AND METHOD}

\section{A. Material}

Three important parameters used to select citrus fruits used as peel sources for natural dyes producing materials in this research include: 1) physical characteristics; 2) harvest amount with comparable quality and harvest time; and 3) the shelf life [20]. Citrus fruits with good quality and quantity of production should be observed to ensure that only citrus fruits with consistent production quantities to be used in research while the citrus fruit shelf life became an important parameter used to obtain insignificant changes in hesperidin pigment levels in a short time [20]. Based on these conditions, citrus reticulata became the material of choice in this research.

To minimize the presence of contaminants that can inhibit the interaction of natural dyes with fabric fibers, TRO (Turkey Red Oil) obtained from UD. Utama Kimia Surabaya-Indonesia is used as a washing agent. Meanwhile, as an intermediary for the interaction between fabric fibers and hesperidin, which have both negative charges, premordanting using alum and soda ash obtained from PT. Brataco Surabaya-Indonesia. Meanwhile, the color locking process is done by using iron (II) sulfate and lime purchased from UD. Jaya Murni Surabaya-Indonesia and also an alum.

\section{B. Preparation of the Dye Extracts from Orange Citrus Peel}

Dyes extract from citrus orange peel material is obtained by the following procedure. In the early stages, the peel is washed, then crushed with a Philips HR7627 food processor to obtain a puree form. After that, the process is continued with the addition of distilled water as much as $1 \mathrm{~L}$ into 100 grams of the obtained puree. The extraction was carried out using water solvents and a specific temperature conditioned by NECSO Lab MS-H280 Pro hot plate. The extraction is carried out until an extract solution was obtained half of the initial volume. In the next step is done the filtration of dye extract using the woven fabric. After the filtration has been completed, the dyes extract solution can be applied in the dyeing process [20].

\section{Washing Procedure}

The process of washing is done at this stage aims to eliminate contaminants in the fabric fibers that will be dyed, so that the quality and quantity of interaction of the mordant compounds on fabric fibers can be increased. The washing process of the cotton fabric sample is carried out by the following procedure. An example of cotton fabrics weighing 2.57 grams soaked in 2 grams/liter TRO for 2 hours. Once the washing process is completed, the cotton fabric is rinsed using distillate water and then dried in the open air. The same washing procedures are also performed in the washing process of the cotton fabric sample with washing time for 4 hours and 6 hours [20].

\section{Mordanting Procedure}

The purpose of the mordanting stages is to increase interaction between fabrics fiber with dye. The process of mordanting at this stage is done with the following procedure. The process of mordanting begins with making a solution of mordant from a mixture of 8 grams of alum and 2 grams of soda ash in 1 liter of water. The homogeneous solubility of both is ensured by stirring with NECSO Lab MS-H280 magnetic stirrer. The process continued with heating the mordant solution uses a hot plate at the temperature of $100{ }^{\circ} \mathrm{C}$ and then into it put 2.57 -gram samples of fabrics under a 1-hour heating process. After 1 hour, a sample of the fabric left immersed in the solution overnight. Once the mordanting process is completed, the fabric sample rinsed and then dried. Once rinsed, samples of fabrics must not be squeezed. A sample of the fabric has dried further ironed in order to get a uniform molecular orientation on 
fiber cotton fabric that will be colored. After the mordanting process is completed, the fabric sample ready for dye [20].

\section{E. Dyeing Procedure}

After the process of washing and mordanting finished, a cotton fabric sample through the dyeing process by pre mordant method using alum that acts as a bridge for the interactions that occur between fabrics fiber and dyes compound which produced from orange citrus peel material. The dyeing process is done with specific formula and conditions, as shown in Table 1 [20].

TABLE I

FORMULA AND OPERATIONAL CONDITIONS OF DYEING

\begin{tabular}{|c|c|}
\hline Preparation & Condition \\
\hline Material to liquor & $1 / 35(\mathrm{gram} / \mathrm{mL})$ \\
\hline Temperature & Room temperature \\
\hline $\begin{array}{c}\text { The weight of the fabric's } \\
\text { sample }\end{array}$ & 0.85 gram \\
\hline Dyeing time & 30 minutes \\
\hline
\end{tabular}

\section{F. Fixation Procedure}

The goal of the fixation stage is to locking the colors that have been interacting with the fabric so it can be obtained a high fastness. Each fixer solution is prepared by dissolving 50 grams of fixer compound in $1 \mathrm{~L}$ of water. The solution is allowed to settle, and then it has been taken a transparent solution. On the next stage, a 0.85 -gram cotton fabric sample was put into a $30 \mathrm{~mL}$ fixer solution and immersed for 10 minutes. The process ends with rinsing and drying the entire fabric sample [20].

\section{G. Color Intensity}

The color intensity of the dye analyzed using the same procedures and instruments as the dyeing process using natural dyes, which published earlier [20]. To determine the dominant dye compound in citrus orange peel extract, it has been done a maximum wavelength analysis of the dye extracts that were obtained. While, to get the difference that comes up from dyeing with a different washing time, dyeing frequency, and fixer type on the dyeing quality, color intensity measurement was performed by Shimadzu Diffuse Reflectant Ultraviolet (DRUV) spectrophotometer UV-2401PC instrument [20]. In DRUV, a low reflectance value will result in high color intensity.

\section{RESULT AND DISCUSSION}

\section{A. The Effect of Washing Time and Fixer Type Effect on The Color Intensity}

The main active component of bioflavonoids found in orange citrus peels is hesperidin, 3',5,7-trihydroxy-4'methoxy-flavanone-7-O- $\beta$-rutinoside [11]. This compound is included in the flavonoid group, which can be used as a producer of yellow in textile materials. Fig. 1 shows the molecular structure of hesperidin, while the interactions formed between the fabric, mordant, hesperidin and three different types of fixers are shown in Fig. 2<smiles>COc1ccc([C@H]2CC(=O)c3c(O)cc(O[C@@H]4O[C@H](CO[C@@H]5O[C@@H](C)[C@H](O)[C@H](O)[C@H]5O)[C@@H](O)[C@H](O)[C@H]4O)cc3O2)cc1O</smiles>

Fig. 1. A molecular structure of hesperidin

TABLE II.

REFLeCtanCe PERCENTAge OF THE SAMPLES RESUlted FROM DyeING WITH DIFFERENT WASHING TIME AND FiXER TYPE

\begin{tabular}{|c|c|c|c|}
\hline No & $\begin{array}{c}\text { Washing Time } \\
\text { (hour) }\end{array}$ & Fixer Type & $\begin{array}{c}\text { Reflectance } \\
(\%)\end{array}$ \\
\hline 1 & 0 & Iron (II) sulfate & 59.99 \\
\hline 2 & 2 & Iron (II) sulfate & 58.69 \\
\hline 3 & 4 & Iron (II) sulfate & 58.41 \\
\hline 4 & 6 & Iron (II) sulfate & 56.96 \\
\hline 5 & 0 & Alum & 86.54 \\
\hline 6 & 2 & Alum & 82.76 \\
\hline 7 & 4 & Alum & 81.56 \\
\hline 8 & 6 & Alum & 78.95 \\
\hline 9 & 0 & Lime & 83.51 \\
\hline 10 & 2 & Lime & 75.70 \\
\hline 11 & 4 & Lime & 75.65 \\
\hline 12 & 6 & Lime & 74.88 \\
\hline
\end{tabular}

Citrus reticulata peel extraction results showed optimum absorption in the visible, ultraviolet region with a maximum wavelength of $385 \mathrm{~nm}$. The pre-mordanting dyeing process of cotton using dyes extracts of Citrus reticulata peels ended with fixation using iron (II) sulfate produces a golden yellow, while in the dyeing process completed by alum and lime, both of which provide a light-yellow color.

The success of producing a distinctive light-yellow color of Citrus reticulata in dyed fibers shows a real mordant role as a liaison interaction between hesperidin and cellulose fibers, which are equally dominated by negatively charged hydroxide groups. Thus, the optimal mordanting procedure is predicted to trigger increased interactions that occur between fibers and dyes. Fig. 2 shows the role of alum as an intermediate that bridges the interaction between fabric fibers and hesperidin. Alum or better known as aluminum sulfate $\left(\mathrm{Al}_{2}\left(\mathrm{SO}_{4}\right)_{3} \cdot 18 \mathrm{H}_{2} \mathrm{O}\right)$ is a chemical compound with +3 central charge atom, each of which interacts with fabric fibers, hesperidin, and soda ash.

A different color appearance was detected on cotton fabric samples that had been dyed and fixed using iron (II) sulfate. The appearance of a distinctive golden yellow color of iron (II) sulfate is due to the dominant structure of the fixer molecule compared to hesperidin. The molecular structure of iron (II) sulfate with smaller size and the steric effect is predicted to be able to fill the void where the fiber does not interact with the mordant. Furthermore, the presence of $\mathrm{Fe}^{2+}$ metal ions in iron (II) sulfate has helped increase the potential for interactions with fiber hydroxide groups that have not yet interacted with mordants. 
In different parts, larger size and steric effects of alum fixers have triggered different phenomena. The appearance of color that is not identical to alum indicates the failure of alum fixer in interacting with fiber even though the presence of $\mathrm{Al}^{3+}$ metal ions in alum should be able to trigger better interaction with parts of fiber that do not interact with mordant. Correspondingly, the size and steric effects of lime fixers, which are much smaller than alum, have shown the same phenomenon. Despite having more enormous potential to interact better with fibers as a consequence of smaller size and steric effects, the lack of chromophore and auxo chromes in lime fixers is not able to bring up the distinctive color of lime. This then makes the dominant influence of pigment and appearance of light-yellow hesperidin. Fig. 2 shows the interaction between the positive charge of the iron (II) sulfate, alum, and lime fixer with the negative charge of the hesperidin functional group.

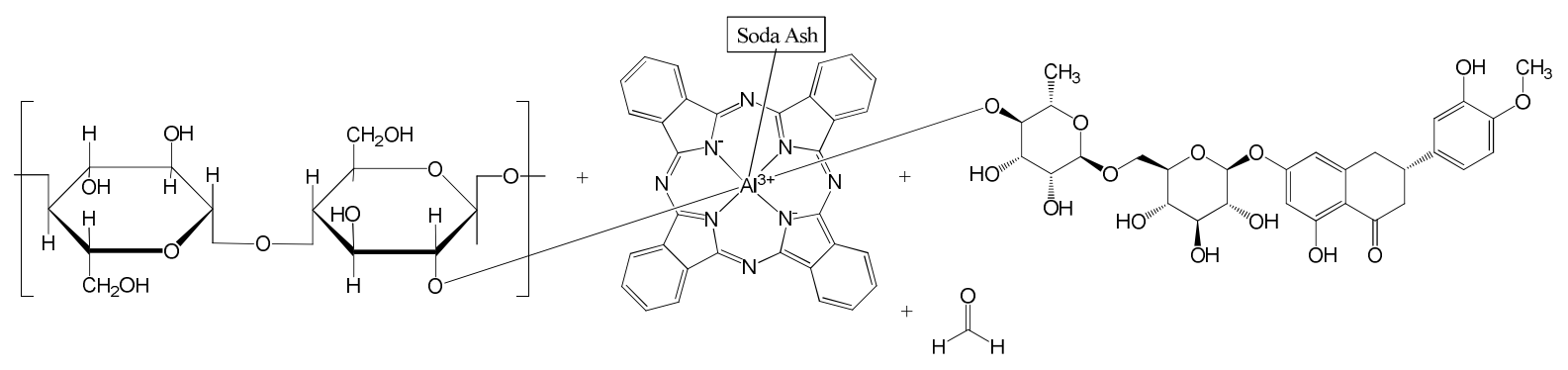

(a)

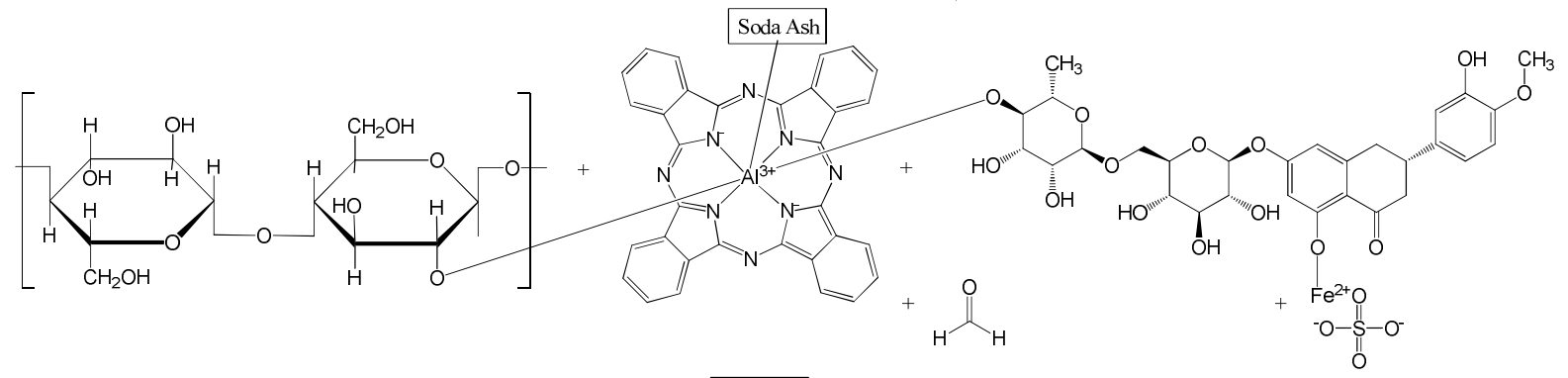

(b)

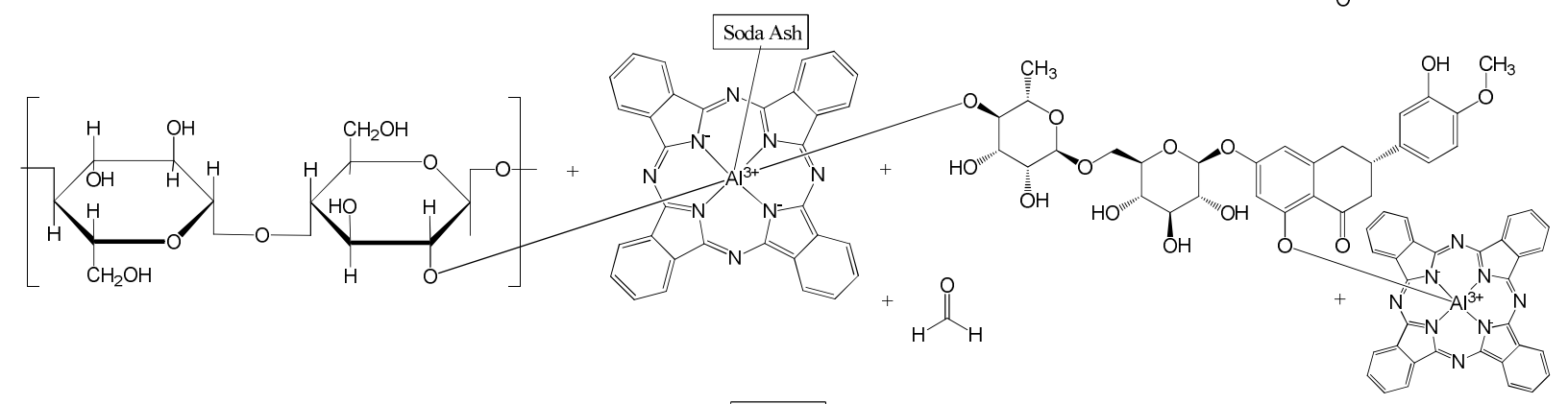

(c)

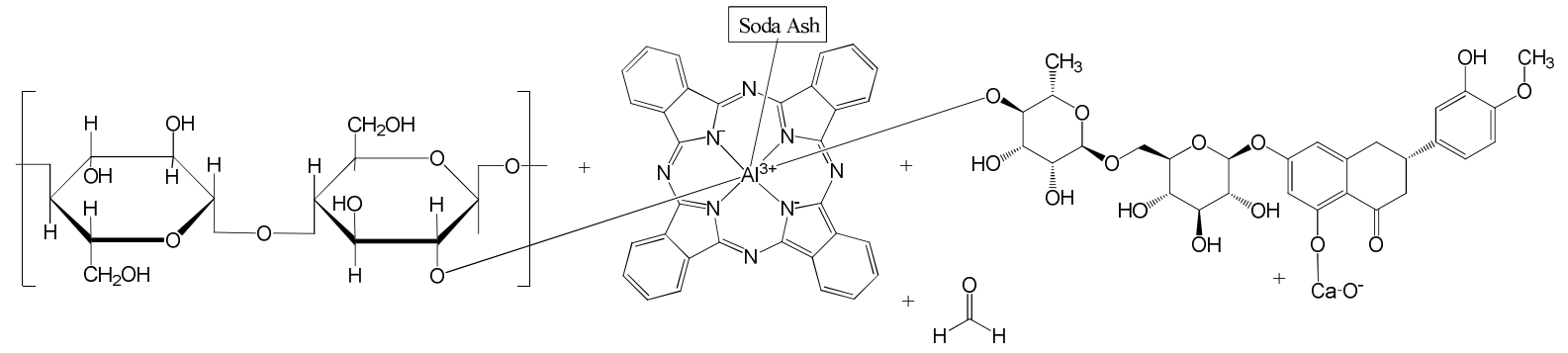

Fig 2. The interaction between fabric fiber, mordant, hesperidin and: (a) iron (II) sulfate, (b) alum, and (c) lime (hypothetic)

Besides, the appearance of a distinctive light-yellow color of Citrus reticulata was also found in the control fabric samples (not through the mordanting) even though the intensity was not as high as the samples of the dyed fabric produced by mordanting. This is closely related to the presence of impurities that have functional groups with a charge similar to mordant [23]-[26]. In this case, the dyeing results will not last long or have low fastness, especially when washing through surfactants [20]. Therefore, it becomes important to remove contaminants from fibers to optimize the color intensity and fastness produced. Table 2 shows the reflectance of the dyed fiber with different washing times. The color intensity, both golden yellow and yellow in the sample of cotton fabrics, will increase as the washing time increases from $0 \mathrm{~h}$ to $6 \mathrm{~h}$.

The percentage reflectance of dyed fibers with different fixer is also shown in Table 2. At the same time, the iron (II) sulfate fixation results showed the lowest reflectance and 
highest color intensity percentage. These results indicate a more dominant low-energy electronic transition (longer wavelengths, $\mathrm{n} \rightarrow \pi *$ ) produced by iron (II) sulfate compared to hesperidin. The moderate reflectance percentage produced by alum fixation results. Although having more varied orbitals than iron (II) sulfate, the lack of alum fixer molecules that successfully fill the void of fiber-mordant interaction has caused the lack of low-energy electronic transitions influence produced by alum fixers. This condition causes lower color intensity produced by alum fixation compared to iron (II) sulfate. In line with this, while being able to fill more of the void of the fiber-mordant interactions, the lack of orbital variation in the lime fixer has made lime fixation results in the highest reflectance percentage. Thus, the fiber-fixer interactions quantity and orbital variations in the fixer molecular structure have influenced each other in determining the final intensity of the dyeing product.

\section{B. The Effect of Dyeing Frequency and Fixer Type Combination on Color Intensity}

The results of repeated dyeing using Citrus reticulata, as shown in Table 3, showing the appearance of (a) a golden yellow color, both in the control and dyed fabrics samples which were mordanted for $6 \mathrm{~h}$ and fixed using iron (II) sulfate; and (b) a light yellow color in the controls and dyed fabrics samples that was mordanted for $6 \mathrm{~h}$ and fixed with alum and lime. In general, both of these results indicate that increasing the dyeing frequency has resulted in a reflectance percentage decrease or an increase in the color intensity percentage. More optimal interaction between fiber, mordant, and hesperidin as the dyeing frequency increases, triggering a more intensive low-energy electronic transition. Thus, a higher color intensity will be obtained.

The appearance of the same color in control and dyed fabric is possible because of the presence of contaminants which capable of replacing the role of the mordant in bridging the interactions between the fabric fibers with the hesperidin and fixers used. In this case, the same interaction will produce the same electronic transition and lead to the creation of the same type of color.

Besides, the light-yellow color formed gradually becomes darker as the frequency of dyeing increases. Increasing the dyeing frequency has given a longer time for more optimal interactions between fibers, mordants, dyes, and fixers. This condition will increase the activity of low energy electronic transitions on the final dyeing product, which in turn forms a darker color.

TABLE III

The REFLeCtANCE of FABric SAMPLES From Dyeing PROCESS WITH DIFFERENT DYEING FREQUENCY AND FIXER TYPE

\begin{tabular}{|c|c|c|c|}
\hline No & $\begin{array}{c}\text { Dyeing Frequency } \\
\text { (times) }\end{array}$ & Fixer Type & $\begin{array}{c}\text { Color Reflectance } \\
(\%)\end{array}$ \\
\hline 1 & 1 & Iron (II) sulfate & 56.96 \\
\hline 2 & 5 & Iron (II) sulfate & 50.22 \\
\hline 3 & 10 & Iron (II) sulfate & 23.71 \\
\hline 4 & 1 & Alum & 78.95 \\
\hline 5 & 5 & Alum & 74.80 \\
\hline 6 & 10 & Alum & 69.50 \\
\hline 7 & 1 & Lime & 74.88 \\
\hline 8 & 5 & Lime & 72.45 \\
\hline 9 & 10 & Lime & 71.83 \\
\hline
\end{tabular}

The appearance of different colors from different types of fixation in this study was more due to the formation of specific chromophores in each fixation product. Different types of chromophores affect different types of orbitals, electronic transitions, as well as absorption wavelengths. In general, absorption at higher wavelengths will result in a darker color appearance.

\section{CONCLUSION}

Efforts to explore, optimize, and standardize natural dyes from a local potential of Indonesia, mainly sourced from plants, have been done. Consistent material characteristics and standard operating conditions are key elements in minimizing color disparities, especially in natural dyes produced from Citrus reticulata peel. Therefore, it is necessary to do exploration, optimization, and standardization of its application on cotton dyeing by the pre-mordant dyeing method. The results showed the appearance of two types of color from the dyeing process with three different fixations, with increased color intensity along with the enhancing of washing time and frequency of dyeing applied. The process of dyeing with fixation using iron (II) sulfate has induced a golden yellow color, while the result of fixation with alum and lime, has made the appearance of a light-yellow color on the sample of cotton fabric. The optimization of washing time and dyeing frequency showed a decrease in reflectance percentage, which is between $86.54 \%-56.96 \%$ along with increased color intensity in washing time on the range 0-6 h; and $78.95 \%-23.71 \%$ on the sample of the fabric with the frequency of dyeing for 1-10 times. All of these standard procedures are expected to produce another new form of natural dye based on the local potential of Indonesia that measured through a systematic and structured experiment.

\section{ACKNOWLEDGMENT}

The authors are grateful to the Directorate of Research and Community Service of the Ministry of Research and Higher Education of the Republic of Indonesia for funding this research through the National Priority Research Program Masterplan of Acceleration and Expansion of Indonesia Economic Development 2017.

\section{REFERENCES}

[1] P. Zhang and Z. Zhou, "Postharvest ethephon degreening improves fruit color, flavor quality and increases antioxidant capacity in 'Eureka' lemon (Citrus limon (L.) Burm. f.),' Sci. Hortic. (Amsterdam)., vol. 248, pp. 70-80, 2019.

[2] B. Singh, J. P. Singh, A. Kaur, and N. Singh, "Phenolic composition and antioxidant potential of grain legume seeds: A review," Food Research International, vol. 101. pp. 1-16, 2017.

[3] K. Pertanian, "Outlook Jeruk," Outlook Komod. Pertan. Sub Sekt. Hortik., p. 2016, 2016.

[4] N. Mahato, K. Sharma, M. Sinha, and M. H. Cho, "Citrus waste derived nutra-/pharmaceuticals for health benefits: Current trends and future perspectives," J. Funct. Foods, vol. 40, pp. 307-316, Jan. 2018.

[5] S. Rafiq, R. Kaul, S. A. Sofi, N. Bashir, F. Nazir, and G. Ahmad Nayik, "Citrus peel as a source of functional ingredient: A review," $J$. Saudi Soc. Agric. Sci., vol. 17, no. 4, pp. 351-358, Oct. 2018.

[6] P. S. Vankar and D. Shukla, "Newer Natural Dyes for Various Textiles," in New Trends in Natural Dyes for Textiles, 2019, pp. 1-69.

[7] L. Titta et al., "Blood orange juice inhibits fat accumulation in mice," Int. J. Obes., vol. 34, no. 3, pp. 578-588, 2010.

[8] Y. Li, A. D. Kandhare, A. A. Mukherjee, and S. L. Bodhankar, 
"Acute and sub-chronic oral toxicity studies of hesperidin isolated from orange peel extract in Sprague Dawley rats," Regul. Toxicol. Pharmacol., vol. 105, pp. 77-85, 2019.

[9] B. K. Purushothaman, U. M. P, and M. S. B. K. M., "Magnetic casein-CaFe2O4 nanohybrid carrier conjugated with progesterone for enhanced cytotoxicity of citrus peel derived hesperidin drug towards breast and ovarian cancer," Int. J. Biol. Macromol., vol. 151, pp. 293-304, 2020.

[10] N. Lahmer, N. Belboukhari, A. Cheriti, and K. Sekkoum, "Hesperidin and hesperitin preparation and purification from Citrus sinensis peels," Der Pharma Chem., vol. 7, no. 2, pp. 1-4, 2015.

[11] S. S. Ferreira, A. M. Silva, and F. M. Nunes, "Citrus reticulata Blanco peels as a source of antioxidant and anti-proliferative phenolic compounds," Ind. Crops Prod., vol. 111, pp. 141-148, 2018.

[12] E. Gómez-Mejía, N. Rosales-Conrado, M. E. León-González, and Y. Madrid, "Citrus peels waste as a source of value-added compounds: Extraction and quantification of bioactive polyphenols," Food Chem., vol. 295, pp. 289-299, 2019.

[13] E. C. Prima, N. N. Hidayat, B. Yuliarto, Suyatman, and H. K. Dipojono, "A combined spectroscopic and TDDFT study of natural dyes extracted from fruit peels of Citrus reticulata and Musa acuminata for dye-sensitized solar cells," Spectrochim. Acta Part A Mol. Biomol. Spectrosc., vol. 171, pp. 112-125, Jan. 2017.

[14] M. Souissi, A. Guesmi, and A. Moussa, "Valorization of natural dye extracted from date palm pits (Phoenix dactylifera) for dyeing of cotton fabric. Part 2: Optimization of dyeing process and improvement of colorfastness with biological mordants," J. Clean. Prod., vol. 204, pp. 1143-1153, Dec. 2018.

[15] K. M. Zia, S. Adeel, F. ur Rehman, H. Aslam, M. K. Khosa, and M. Zuber, "Influence of ultrasonic radiation on extraction and green dyeing of mordanted cotton using neem bark extract," J. Ind. Eng. Chem., vol. 77, pp. 317-322, 2019.

[16] Ö. E. İşmal and L. Yıldırım, "Metal mordants and biomordants," in The Impact and Prospects of Green Chemistry for Textile Technology, 2019, pp. 57-82.

[17] K. Phan, E. Van Den Broeck, V. Van Speybroeck, K. De Clerck, K. Raes, and S. De Meester, "The potential of anthocyanins from blueberries as a natural dye for cotton: A combined experimental and theoretical study," Dye. Pigment., vol. 176, 2020.

[18] O. Kakuee, V. Fathollahi, P. Oliaiy, and S. Mesbahi, "Investigation of mordants for dyeing of yarns in ancient Persian carpets (15th-17th century) by IBA methods," Nucl. Instruments Methods Phys. Res. Sect. B Beam Interact. with Mater. Atoms, vol. 450, pp. 294-298, 2019.

[19] T. Basitah, "Extraction, Characterization and Application of Natural Dyes from the Fresh Rind of Index Colour 5 Mangosteen ( Garcinia mangostana L .)," Int. J. Chem. Mol. Nucl. Mater. Metall. Eng., vol. 9, no. 7, pp. 883-886, 2015.

[20] N. Kusumawati, A. B. Santoso, M. M. Sianita, and S. Muslim, "Extraction, characterization, and application of natural dyes from the fresh mangosteen (Garcinia mangostana L.) peel," Int. J. Adv. Sci. Eng. Inf. Technol., vol. 7, no. 3, pp. 878-884, 2017.

[21] N. Kusumawati, T. Kostiari, and A. B. Santoso, "The influence of washing process using TRO on indigosol dyeing quality, leaching percentage, and mechanical strength of mori fabric," Res. J. Pharm. Biol. Chem. Sci., vol. 6, no. 6, pp. 55-63, 2015.

[22] A. K. Samanta and A. Konar, "Dyeing of textiles with natural dyes," Nat. Dye., vol. 3, no. 30-56, 2011.

[23] N. Kusumawati, S. Muslim, and A. Kistyanto, "Operational conditions optimization on blacu fabric dyeing technology. Case study: mordanting influence on naphtol color quality and mechanical strength of blacu fiber," Res. J. Pharm. Biol. Chem. Sci., vol. 7, pp. 672-682, 2016.

[24] N. Kusumawati, S. Samik, A. B. Santoso, and A. Wijiastuti, "Development of Textile Natural Dyeing using Hybrid Dyes from Mango Leaves Turmeric," in Seminar Nasional Kimia-National Seminar on Chemistry (SNK 2018), 2018.

[25] N. Kusumawati, A. Kristyanto, and S. Samik, "Exploration of Natural Dyes by Using a Combination of Caesalpinia sappan and Leucaena leucocephala L. Leaves.," in National Seminar on Chemistry 2019 (SNK-19), 2019.

[26] P. Zhang and Z. Zhou, "Postharvest ethephon degreening improves fruit color, flavor quality and increases antioxidant capacity in 'Eureka' lemon (Citrus limon (L.) Burm. f.)," Sci. Hortic. (Amsterdam)., vol. 248, pp. 70-80, Apr. 2019. 